\title{
More than half the Earth
}

\author{
This month we highlight Asia, a region with important biodiversity and palaeontological heritage, and a major \\ growth area for scientific research.
}

t's t's the largest continent geographically, home to well over half of the Earth's human population, and is one of only two continents that has biomes stretching latitudinally from polar right through to tropical. Yet, it can be overlooked by the ecology and evolution community in favour of the continents that have had a more obviously pivotal role in human evolution (Africa), have a more iconic forest biodiversity and role in the global carbon cycle (South America), have a more evolutionarily unique mammalian fauna (Australia), or have historically been the source of more scientific papers (Europe and North America). There are, however, many reasons why we should be paying ever closer attention to Asia, several of which are illustrated by articles in this issue of Nature Ecology \& Evolution.

The giant panda is an icon of both global and Asian conservation biology, the symbol of the World Wide Fund for Nature (http:// wwf.panda.org), and therefore the target of intense conservation effort. In 2016, these efforts led to the International Union for Conservation of Nature downgrading the species from endangered to vulnerable. However, $\mathrm{Xu}$ et al. report that this may be an optimistic picture, because remote sensing data show that the giant panda's habitat is more fragmented now than it was when it was first added to the endangered list. This highlights the need for a variety of methods for assessing risks to biodiversity rather than dependence on traditional metrics, as exemplified in a recent Perspective on linking remote sensing to monitoring on the ground ${ }^{1}$.

Given the proportion of the global population that lives in Asia, progress towards sustainable development on that continent is critical for planetary sustainability. In addition to biodiversity conservation, food security and climate change stand out as major challenges. Food security depends on the ability to control agricultural pests such as the tobacco cutworm, Spodoptera litura, a polyphagous moth of major concern whose larvae feed on a variety of crops in east Asia. Cheng et al. address the issue using genome sequencing, a technology that has been invested in heavily by China to the benefit of the global scientific community. Their study sheds light on how the pest has evolved and suggests ways in which it could be controlled. Climate change is the focus of the Article by Huang et al., in which the authors apply the concept of climate velocity ${ }^{2}$ to the question of how the velocity at which vegetation productivity shifts polewards under climate change relates to the shift in temperature. Understanding this is important for projecting changes in the carbon cycle, which itself feeds back to the changing climate.

China recently hosted the inaugural meeting of the Global Forest Biodiversity Initiative (http://www.gfbinitiative.org/ symposium 2017), which brings together tree-level data from over 1.2 million plots across the globe, something that presents challenges in terms of data stewardship and ownership. The choice of China as a location is appropriate given that it has conducted the largest afforestation programme of any country in an attempt to mitigate climate change. However, the devil is - as ever - in the detail, with the extent and quality of forest cover depending very much on definitions, and a considerable amount of afforestation occurring in areas that are of debateable suitability ${ }^{3}$. Something that could be of great benefit to effective tree-planting programmes is an improved understanding of the relationship between forest functions and biodiversity, and a study in this issue uses data from an Asian site to address such a question. O'Brien et al. explore the relationship between the species diversity of a tree community and its resistance to drought, showing that reduced water competition in more diverse communities makes them more drought tolerant.

Exciting results are also burgeoning from researchers in the region. Two studies in this issue from researchers in Asia look at fundamental questions in evo-devo. The phylotypic stage of development is widely conserved across vertebrates, more so than the stages that both precede and succeed it. Hu et al. show that genes involved in the phylotypic stage have pleiotropic roles elsewhere in development, a constraint that might help to explain the conserved bodyplan of vertebrates. Okamoto et al. look at the classic case of vertebrate limb development, and show that the limb muscle development mechanism found in bony fish is present in cartilaginous fish as well, pushing our understanding of the early evolution of vertebrate appendages deeper into the past.

No discussion of Asia in this journal would be complete without including palaeontology. It is not necessarily a surprise that such a large landmass has offered famous fossils such as the Chengjiang biota of the Cambrian, the first insights into feathered dinosaurs, and the Neanderthals and Denisovans of the Altai cave, but it is nevertheless worth celebrating. China, in particular, has offered up some particularly impressive finds in recent years. However, the large population of the region does pose a threat to its palaeontological heritage as well as its biodiversity, as illustrated by the example of the Weng'an biota of the Precambrian that is under threat from the agricultural need for phosphate mining ${ }^{4}$.

The strength of research output from Asia, and the strong links between researchers in Asia and the rest of the world, is illustrated by some important conferences on the calendar for 2018 (https:// natureecoevocommunity.nature.com/ channels/536-on-the-road/posts/20718conferences-2018). The Society for Molecular Biology and Evolution is holding its main annual meeting in Yokohama, Japan (http://smbe2018.jp/) and also a satellite meeting on microbial evolution in Assam, India (http://www.smbe.org/smbe/HOME/ TabId/37/ArtMID/1395/ArticleID/55/ SMBE-Satellite-Meeting-in-India-ThisDecember.aspx). Kuching in Malaysia is hosting both the International Marine Conservation Congress (http://conbio.org/ mini-sites/imcc5/) and the Association for Tropical Biology and Conservation annual meeting (http://tropicalbiology.org/atbcmeetings/annual-meetings/). The coming year also sees the inaugural Asian Evolution meeting in Shenzhen, China (http://www. asianevo.org/index.html). These are just some of the exciting events in Asia and elsewhere where the Nature Ecology \& Evolution editors hope to get out and about in the research community.

Published online: 24 October 2017 DOI: 10.1038/s41559-017-0369-2

References

1. Bush, A. et al. Nat. Ecol. Evol. 1, 0176 (2017).

2. Loarie, S. R. et al. Nature 462, 1052-1055 (2009).

3. Ahrends, A. et al. Proc. R. Soc. B 284, 20162559 (2017).

4. Yang, H., Ma, M., Flower, R. J., Thompson, J. R. \& Ge, W. Nat. Ecol. Evol. 1, 1048-1049 (2017). 